\title{
The Biological Serial Record Center
}

\author{
BY MILDRED BENTON
}

The Biological Serial Record Center (BSRC) is one phase of a continuing effort to improve the flow of information to the scientific community. It will bring together in one location information hitherto scattered or inaccessible; provide a census of existing life science serials, as well as those that have ceased publication; indicate what portion is available to American biologists; and, in general, give access to worldwide data useful for studies in depth of the scientific serial literature in at least one subject discipline.

Implemented by the Biological Sciences Communication Project of the American Institute of Biological Sciences ${ }^{1}$ and supported by a three-year grant ${ }^{2}$ from the National Institutes of Health, the center was activated on August 20,1962, with offices in Suite 700, Headquarters Building, 2000 P Street, N.W., Washingon 6, D.C.

The goal towards which the staff of ten (two full-time, eight part-time) is working is a descriptive record on cards of the serial publications (periodicals, proceedings, transactions, annual reports, etc.) of the world related to the life sciences (agricultural, biological, medical).

Interrelated are these objectives: to organize, analyze, and disseminate continously the comprehensive data obtained. A few details are outlined for each objective.

\footnotetext{
1 The Project was transferred to the George Washington University on June 1, 1963.

${ }^{2}$ Grant GM 11711-01.
}

Miss Benton is Chief of the Biological Serial Record Center, Suite 700, 2000 P Street, N.W., Washington 6, D.C.

\section{To OBTAIN THE FOLLOWING DATA PERTINENT TO EACH SERIAL TITLE}

A. Title and subtitle.

B. Title abbreviation (abbreviations are those found, in the following order of preference, in (1) Chemical Abstracts; (2) Biological Abstracts; (3) Bibliography of Agriculture; (4) Index Medicus; (5) other.

C. Publisher and publisher's address.

D. Editor (not included for society and similar journals, the editors of which frequently change).

E. Editorial policy (included only when significant).

F. Nature of contents (e.g., research, review, or popular articles; abstracts; collection of reprints; book reviews; biographic information; bibliographies; indexes; advertising).

G. Price and/or availability for exchange.

H. Language.

I. Copyright.

J. Type, or sponsorship (e.g., society, institute, laboratory, museum, educational, commercial, industrial, government).

K. Format (size, illustrations, figures, charts, general makeup (e.g., one or two columns to a page, average number of pages). 
L. Frequency.

M. Volumes issued (v.1, no.1 and datelatest found).

N. Coverage (by abstracting and indexing services, e.g., Biological Abstracts, Chemical Abstracts, etc.).

O. Subject (based on numerical subject outline devised for use in coding for mechanical retrieval).

P. Area (country in which published).

Q. Location (library in which serial was located and examined).

R. Reference (source, or lists where title was discovered).

S. Date (date searched).

Inasmuch as it is not the intention to accumulate publications but rather to accumulate information about them, access to library collections is a prime requisite. The BSRC is most fortunate in having the privilege of utilizing, for the most part, five Washington area libraries designated as cooperating libraries, not only because of their important holdings in biology subjects but also because of their representation on a BSRC advisory committee which meets at intervals to advise on problems and procedures. These libraries are the ones in which the above listed data are found-Library of Congress, National Agricultural Library, National Library of Medicine, and the libraries of the Department of Interior and the Smithsonian Institution.

\section{TO STORE DATA IN A RETRIEVABLE FORM}

A preliminary or working file is presently managed by the use of edge-notched cards. A second phase of the program provides for conversion of the working file to IBM punched cards. As the center has been in active operation for little more than a year, Phase I, the accumulation of titles, is still under way and few cards have been coded. An alphabeticalnumerical form of coding guide has, however, been devised.

\section{TO ANNOUNCE NEW SERIAL TITLES}

Arrangements have been made to list newly published journal titles in the American Institute of Biological Sciences Bulletin as a regular feature.

\section{TO ANALYZE THE SERIAL LITERATURE OF BIOLOGY}

The volume of completed cards is not yet large enough to attempt any analysis of the data by subject content, geographical distribution, and the like, but answering of queries is anticipated.

\section{TO PUBLISH AND DISSEMINATE INFORMATION}

One publication, Aquatic Biology Serials has already resulted from concentrating, during the first few months of operation, on describing the serial literature in one subject area. Current work is devoted to serials which include drug information. Projected for the near future are investigations of the serial publications concerned with aspects of human development, and of those relating to food and nutrition. Other subject areas will be covered as time permits.

Although "one stop shopping" for the world's biological journals is one step nearer, the road ahead for BSRC is a long one, for in its files are some fortyfive thousand titles. These titles were obtained from library lists and catalogs, from major bibliographic tools, from library-oriented individuals traveling abroad, from publisher's announcements - in fact, from all possible sources. Undoubtedly there are other, untapped resources, and, if there are, BSRC hopes to learn about them.

By adhering to a policy of cooperation with other information collecting centers, and by remaining alert to further opportunities for achieving expanded coverage of biological serial literature, it is the expectation that a more comprehensive final product will ultimately become available for all who care to use it. 